\title{
Chapter 4 \\ Climate Change, Agricultural Production, and Poverty in India
}

\author{
Saibal Kar and Nimai Das
}

\begin{abstract}
The low-income households in the South Asian countries are highly sensitive to climate-intensive sectors like agriculture, mainly due to the negative impact of climate change on the food production system as a whole. Climateinduced supply shortfalls in agriculture, and consequent food price shocks may adversely affect consumption in these households. The tension between economic development, climate change, and agricultural production offers a challenging research question not dealt with in recent studies for India. We explore the effect of climate change on farmland value and use a counterfactual measure of the farm revenue on rural consumption expenditure. We found a discerning impact of the climate change on the net revenue and well-being of the rural people. A theoretical exercise generalizes the empirical findings.
\end{abstract}

Keywords India $\cdot$ Poverty $\cdot$ Agriculture $\cdot$ Food production $\cdot$ Climate change

JEL Classification C23 - C68 - Q11 • Q21

\subsection{Introduction}

The Intergovernmental Panel on Climate Change (IPCC) observed that the Earth's current climatic system, when compared with how it was in the pre-industrial era, has visibly changed at both global and local levels. The changing climate of the

\footnotetext{
S. $\operatorname{Kar}(\bowtie)$

Centre for Studies in Social Sciences, Calcutta, India

e-mail: saibal@cssscal.org

S. Kar

Institute for the Study of Labor, Bonn, Germany

N. Das

Institute of Economic Growth, New Delhi, India

e-mail: nimai@iegindia.org
} 
Earth's surface systems is now an integral issue in almost all international policy forums. Since climate change is a significant concern for the global environmental order, a large number of studies have been undertaken over the last three decades in order to explore its social and economic impacts. Not surprisingly, global warming affects different regions and sectors differently based on their sensitivity and adaptive capacity, and different groups of people are exposed to different degrees of vulnerability caused by the same degree of climate change (Forsyth 2000). The vulnerability of natural and human systems, especially in weaker economies, and their adaptations to climate change has attained critical dimensions. Nevertheless, the effects are expected to hit developing countries the hardest owing to their relatively high dependence on climate-sensitive natural resources in the base sectors like agriculture. This chapter is an attempt to measure the effects of rising temperatures and irregular rainfall on the crop production patterns in India between 1997 and 2008. The empirical findings are supported by a theoretical exercise where we model the welfare impact with the use of a general equilibrium framework.

It is well known that climate change has several adverse effects on natural ecosystems and humankind, manifested through declining rainfall and rising temperatures. Besides, severity of extreme climates (drought/flood) that threaten food production and livelihood in a country has emerged as a major fallout of climate changes (IPCC 2012). Crop production in developing and transition countries still relies heavily on the carrying capacity of the surrounding ecosystems for adequacy of water, soil quality, climate regulations, and other attributes associated with a cleaner atmosphere. Despite technological advances in crop production and irrigation systems, local weather and general climate continue to play decisive roles. In fact, the climatic variations affect the supply side (crop production) directly by changes in the agro-ecological conditions. The demand side, on the other hand, is affected via growth and distribution of incomes (Schmidhuber and Tubiello 2007), which too are related to human adaptations of climate change. The response to climate-induced market contraction, therefore, seems to impart serious socioeconomic consequences, particularly for those in agriculture. Recently, Tirado et al. (2010) offer a vivid analysis of a countrywide impact of climate change on food production and nutrition of people, identifying two major challenges threatening current as well as future food production. These are (i) climate change and the consequent loss of ecosystems and (ii) the growing use of biofuel-based crops that adversely affect land and soil fertility.

The implications are obviously quite pervasive. At present, more than 800 million people living in tropical and subtropical countries are food insecure (Narain et al. 2009). The situation is likely to worsen-the number of food-insecure people is likely to increase as changes in extreme weather events and mean climate parameters negatively affect crop, animal yields, and agro-ecosystem resilience. The situation has deteriorated for the world food system, which has responded negatively to climate-induced supply shortfalls in the agricultural sector. Higher commodity prices appear to be direct consequences of these changes, manifested through increasing input prices. These directly contentious elements 
not only make the present study quite interesting, but also a vexing exercise empirically.

Note that, agricultural inputs and natural resources are critical determinants of food supply. Degradation of natural resources (like soil, forest, and water) hampers supply of inputs. Lower availability of and access to water, fertilizers, pesticides, energy, etc., in turn, affects agricultural productivity and food production. Most variables in our structure are, therefore, 'endogenous.' Nevertheless, in most developing countries, there is a rising inclination toward use of chemical fertilizers and pesticides for enhancing crop productivity. However, this results in depletion of soil nutrients. Fortunately, this trade-off is directly measurable. In the medium to long run, the food supply is certainly going to fall and create pressure on prices and, hence, on food security for millions of poor people in developing countries.

Further, note that the world food production slowed down in the decades of the 1980s and 1990s. Growth rates of rice and wheat have begun to stagnate in Asia. In India, the growth rate of food grains including rice was lower than the population growth rate during the 1990s (see Fig. 4.1). Although the growth rate of wheat was moderately high as compared to the population growth during the same time, wheat grew at a rate below $3 \%$ in the 1990s against its best performance of above $9 \%$ in the 1960s. This mismatch between growth of food crop production and population has been quite alarming since the 1990s. Further, several studies predicted that despite a substantial increase in national food grain production in India, the productivity of some important crops (like rice and wheat) could decline considerably with climatic changes. Due to a $2-3.5^{\circ} \mathrm{C}$ rise in temperature,

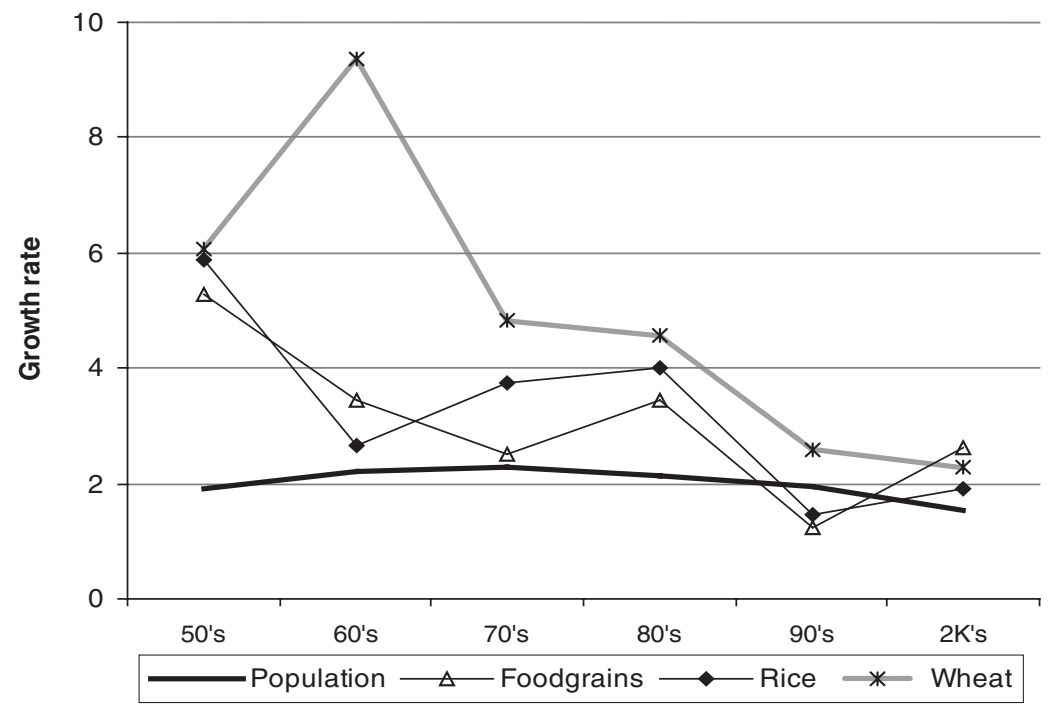

Fig. 4.1 Growth rates of population, all food grains, rice, and wheat in India. Note Decadal growth rates estimated from the Reserve Bank of India database between 1950-1951 and 20102011 
accompanied by a 7-25\% change in precipitation, farmers may lose net revenues between 9 and $25 \%$, which must adversely affect GDP by 1.8-3.4\% (Kumar and Parikh 2001; Sanghi and Mendelsohn 2008). Notwithstanding evidence suggesting that higher precipitation is expected to increase net revenue from agriculture, the overall negative impact due to temperature increase more than compensates for the small positive impact due to higher precipitation (the former effect is seen to dominate the latter for India).

The World Bank comments that cooler regions around the Himalayas will be net gainers of climate variability, whereas the dryer regions of Rajasthan (western India) will be adversely affected. Disproportionate effects of climate change have been noticed at local levels giving legitimacy to several microcase studies that together can offer an understanding of the bigger picture. The small and marginal farmers are likely to be victims of such climatic stresses because affluent farmers may benefit due to their high adaptive capacity (access to credit, larger market share, crop insurance, etc., facilitate adaptation, Brine et al. 2004). Consequently, the costs of climate change are not borne uniformly by agricultural groups, which are heterogeneous in terms of assets, human capital, and access to credit. The demand-side effects on prices will also be uneven across income groups.

\subsection{Methodology and Dataset}

The recognition of climate change as an important economic phenomenon has been accommodated by both partial equilibrium and general equilibrium approaches using the well-known general circulation model for a forecast of the climate change associated with emission of greenhouse gases. However, in contrast to aggregative (structural) general equilibrium models, the partial equilibrium models are capable of producing quantitative analysis using specific factors of importance at the local or regional levels (Palatnik and Roson 2009). The contemporary empirical literature on estimating climate change-induced impacts on farming systems is rooted in three predominant approaches: crop simulation models, agronomic statistical models, and hedonic price models (Jacoby et al. 2011; Hertel and Rosch 2010; Zhai et al. 2009; Schlenker and Roberts 2009). ${ }^{1}$

An alternative to the crop simulation approach is to estimate statistical relationships between crop yields, on the one hand, and climatic parameters, especially temperature and precipitation, on the other, using relatively less calibrated data. This is readily implemented for large geographic areas (Hertel and Rosch 2010; Lobell and Burke 2010). Finally, the so-called hedonic approach for analyzing the impact of climate change on farming systems (Jacoby et al. 2011) is known as the Ricardian Model that predicts choice of the highest yield on any given set of

\footnotetext{
${ }^{1}$ See also Lobell and Burke (2010). Inferences made by the structural approach are rooted in laboratory experiments and, hence, generate biased results for the larger area studies with diverse agricultural production systems (Nhemachena et al. 2010).
} 
land. The approach focuses on the impact of climate on land values, not yields. This technique draws heavily on the underlying observation by Ricardo (1817) that under competition, rental value of land reflects net productivity/profit from the land. The main advantage of this approach is that it automatically takes the farmlevel adaptations into consideration, while assessing the direct effect of climate on crop performance.

This is what we also adopt in this paper (also see Mendelsohn et al. 1994; Nhemachena et al. 2010; Kurukulasuriya and Mendelsohn 2008; Kumar and Parikh 2001). By looking at the cross section of farms, the Mendelsohn version of the Ricardian technique examines farmers' behavior to mitigate the problems associated with suboptimal climatic conditions. The comparison across space tenders efficient adaptation responses to avoid overestimation of the damages associated with any deviation from the optimum (Sanghi and Mendelsohn 2008, p. 656). Fundamentally, the Ricardian function is a locus of the maximum net revenue choices for different crops, which have their own net revenue functions with respect to climate (Seo and Mendelsohn 2007, p. 6).

Let us briefly explain how the Ricardian approach captures farm-level adaptation for changing scenarios of climate. In Fig. 4.2, the revenue functions for different crops $C_{1}, C_{2}$, etc., are plotted against the exogenous weather conditions. The response of a crop, say $C_{2}$, with respect to the weather conditions $W_{1}, W_{2}$, etc., should be concave to the weather axis, which means that a given climate (suppose $W_{2}$ ) is required to attain the best possible level (the peak). For each crop, there is a known weather condition at which that crop grows optimally during a crop season. Therefore, different crops attain their optimum level at different climatic conditions. This means a rational farmer may switch to $C_{3}$ from $C_{2}$ when the climate condition changes from $W_{2}$ to $W_{3}$. In view of this, a representative farmer may respond along the loci of optimum levels for the crops against climate change scenarios. Nevertheless, the movement along this envelope curve for the

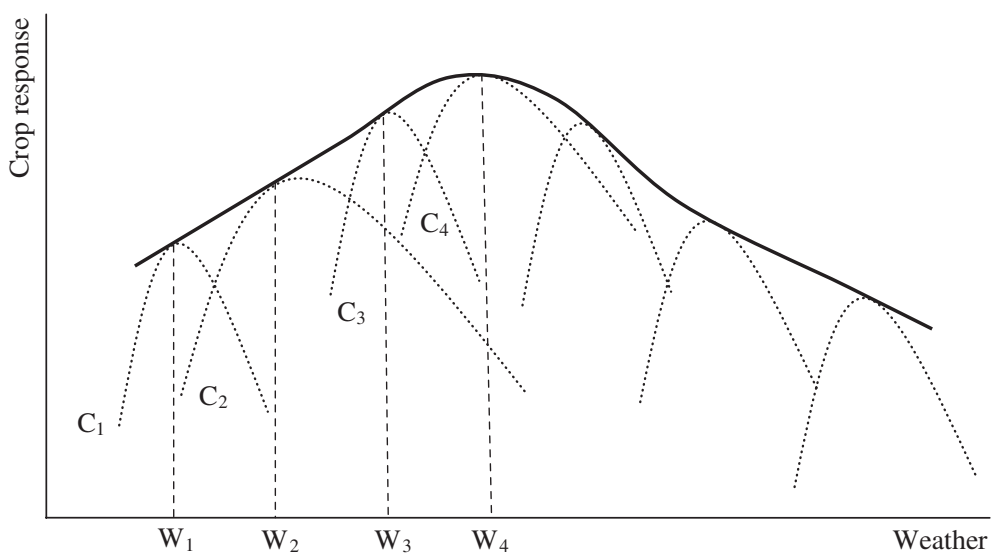

Fig. 4.2 Crops response against changing climatic conditions 
farmers against changing climate is costly and involves economic decisions such as the choice between alternative input requirements demanding solution of a constrained optimization problem. Overall, the relevant decision variables should be the returns from farmland, which usually is the net revenue from cultivation. Based on the structure, the model is specified as:

$$
\begin{aligned}
R=\alpha & +\beta_{1 j} \mathrm{NT}_{j}+\beta_{2 j} \mathrm{NT}_{j}^{2}+\beta_{3 j} \mathrm{NT}_{j}^{3}+\beta_{4 j} \mathrm{NR}_{j}+\beta_{5 j} \mathrm{NR}_{j}^{2}+\beta_{6 j} \mathrm{NR}_{j}^{3} \\
& +\beta_{7 j} \mathrm{NT}_{j} \mathrm{NR}_{j}+\lambda_{1} \mathrm{IRR}+\lambda_{2} \mathrm{HYV}+\lambda_{3} \mathrm{IRRxHYV}+\lambda_{4} \mathrm{HDI} \\
& +\gamma_{m} \mathrm{SD}_{m}+\theta_{n} \mathrm{YD}_{n}+u,
\end{aligned}
$$

where NT $=$ normal temperature $(j=$ January, April, July, and October; or kharif, rabi, and zaid), $\mathrm{NR}=$ normal rainfall, $\mathrm{IRR}=$ irrigation intensity, $\mathrm{HYV}=$ intensity of high-yielding seeds, IRRxHYV = interaction between high-yielding variety (HYV) and irrigated areas to reorganize their collective effect for green revolution, HDI $=$ value of human development index, SD = soil type dummy $(m=1-6$ for 7 soil types), $\mathrm{YD}=$ year dummy $(n=1997-2008$ for 13 years $)$, and $\mathrm{u}=$ error term.

First, we consider eight climate variables-daily temperature $\left({ }^{\circ} \mathrm{C}\right)$ and monthly precipitation $(\mathrm{mm})$ for the months of January, April, July, and October, which strongly correspond to the cropping seasons in India. For example, January represents the growing season for winter crops. Similarly, April is the growing season for summer crops. The month of July, the monsoon season, is the growing season for kharif crops. October is the harvesting season for monsoon crops as well as sowing season for winter crops. However, inclusion of every month of the year in the analysis may lead to insignificant results, since the climates of many months are closely related to the preceding or following months. Thus, an effort has been made to capture any intra-season climatic vacillation in the second model by considering the average value of climate variables such as the daily temperature and monthly rainfall for each individual cropping season in India. Notably, as per the national meteorological department, the country is largely subject to four seasons: winter (January and February), summer (March-May), monsoon (JuneSeptember), and post-monsoon (October to December). The crops are broadly divided into three categories, namely kharif, rabi, and zaid crops. The season for kharif or monsoon crops starts from June and ends in September. The rabi or winter season is during October to February, and the zaid or summer crop season is between March and May.

For the second model, we consider six climate variables-temperature and precipitation for the kharif, rabi, and zaid seasons. Since our analysis is at the state level, statewide assessment of climate variables, spread over particular places in the countryside, involves a methodological intricacy to determine the climate surface for a state. In the literature, the climate surface of a region is estimated for a climatic variable using all the places which have recorded the values of that variable within a 600-mile radius. Nevertheless, the weather stations closer to a given geographical center representing state surface climate would usually have more weight in the state surface climate. Therefore, the weighted regression should be run using the weight as the inverse of square root of a station's distance to the 
Table 4.1 Regression results for temperature in Madhya Pradesh

\begin{tabular}{l|l|l|l|l}
\hline & Winter & Summer & Monsoon & Fall \\
\hline Constant & $59.73^{*}$ & $122.05^{*}$ & $52.71^{*}$ & $47.35^{*}$ \\
\hline Latitude & $-3.14^{*}$ & $-2.35^{*}$ & $-1.24^{*}$ & $-2.262^{*}$ \\
\hline Longitude & $6.88 \mathrm{E}-4$ & $5.34 \mathrm{E}-4^{*}$ & $4.37 \mathrm{E}-4^{*}$ & -1.102 \\
\hline Altitude & $-2.05 \mathrm{E}-3^{*}$ & $-3.46 \mathrm{E}-4^{*}$ & $-3.21 \mathrm{E}-3$ & $1.35 \mathrm{E}-4$ \\
\hline Shoreline & $8.56 \mathrm{E}-2$ & $5.91 \mathrm{E}-4$ & $6.12 \mathrm{E}-3$ & $8.56 \mathrm{E}-2^{*}$ \\
\hline Latitude squared & $-4.23 \mathrm{E}-2$ & $-4.35 \mathrm{E}-2$ & $-1.73 \mathrm{E}-3$ & $2.36-2$ \\
\hline Longitude squared & $-6.66 \mathrm{E}-3$ & $5.34 \mathrm{E}-3$ & $-2.76 \mathrm{E}-4$ & $-1.26-2^{*}$ \\
\hline Altitude squared & $4.40 \mathrm{E}-7^{*}$ & $1.91 \mathrm{E}-6$ & $3.25 \mathrm{E}-5$ & $-4.84 \mathrm{E}-7^{*}$ \\
\hline Shoreline squared & $-1.79 \mathrm{E}-5$ & $-2.33 \mathrm{E}-5^{*}$ & $-4.23 \mathrm{E}-5$ & $-1.69 \mathrm{E}-5^{*}$ \\
\hline Latitude $\times$ longitude & $5.16 \mathrm{E}-2$ & $3.25 \mathrm{E}-3$ & $-2.85 \mathrm{E}-2$ & $3.24 \mathrm{E}-2$ \\
\hline Latitude $\times$ altitude & $2.36 \mathrm{E}-4$ & $1.55 \mathrm{E}-4^{*}$ & $5.24 \mathrm{E}-3$ & $-1.36 \mathrm{E}-3$ \\
\hline Latitude $\times$ shoreline & $-1.02 \mathrm{E}-4$ & $-2.13 \mathrm{E}-4$ & $-2.42 \mathrm{E}-4$ & $-2.15 \mathrm{E}-4$ \\
\hline Longitude $\times$ altitude & $-1.04 \mathrm{E}-4$ & $3.64 \mathrm{E}-4$ & $-1.14 \mathrm{E}-4^{*}$ & $-1.44 \mathrm{E}-4$ \\
\hline Longitude $\times$ shoreline & $-9.29 \mathrm{E}-4$ & $-4.07 \mathrm{E}-4$ & $-5.57 \mathrm{E}-3 *$ & $-6.09 \mathrm{E}-4^{*}$ \\
\hline Altitude $\times$ shoreline & $-4.06 \mathrm{E}-7$ & $-7.32 \mathrm{E}-6$ & $-3.28 \mathrm{E}-6$ & $-7.14 \mathrm{E}-6$ \\
\hline R-squared & 0.53 & 0.52 & 0.65 & 0.61 \\
\hline Observations & 79 & 79 & 79 & 79 \\
\hline Statically & & & \\
\hline
\end{tabular}

*Statistically significant at the $5 \%$ significance level

state geographical center. In practice, a climate variable like temperature (suppose $T$, which is essentially an average of maximum and minimum temperatures) for 30 years (we consider 1961-1990) is nonlinearly regressed on latitude, longitude, altitude, and shoreline distance including its corresponding square and intersection terms. The predicted normal temperature $(\overline{\hat{T}})$ is used to estimate the Ricardian model. Therefore, a total of $152(2 \times 4 \times 19)$ separate regressions, each for average temperature or total rainfall, are conducted for the respective four seasons of the nineteen states. The sample regression results for the state of Madhya Pradesh (the central province, as an example) are depicted in Table 4.1 for the temperature variables using 30-year averages for temperature for the period 1961-1990 for 111 weather stations in India.

\subsubsection{Estimation of the Ricardian Model}

To estimate the model 4.1, we used pooled cross-sectional and time series data at the state level, for India, over the last two decades. The states are considered as units of analysis, and substantial variations in climatic, geographic, and economic factors exist among states. In India, many nodal agencies are involved in the collection and compilation of data on various aspects like agriculture, poverty, and climate. For the agricultural sector, we use data from the Directorate of Economics and Statistics, Department of Agriculture and Cooperation, Ministry of Agriculture, Government of India, covering 
agricultural area, production, yields, cost of cultivation, etc., by crops and by states. Historical data on two usual indicators of climate change, namely temperature and precipitation, are available from the Indian Meteorological Department. The Planning Commission of India and the Reserve Bank of India provide databases for the socioeconomic variables. ${ }^{2}$

The use of official data for the Ricardian model involves some special treatments, which are described below. The dataset covers nineteen major states producing $90 \%$ of agricultural output. These include Andhra Pradesh, Assam, Bihar, Chhattisgarh, Gujarat, Haryana, Himachal Pradesh, Jharkhand, Karnataka, Kerala, Madhya Pradesh, Maharashtra, Odisha, Punjab, Rajasthan, Tamil Nadu, Uttar Pradesh, Uttaranchal, and West Bengal over 13 years between 1996-1997 and 2008-2009. These states spread across the diversified agro-climatic zones such as north and northeastern Himalayan to the Gangetic plains of east and the plateau and hills of central, southern, and western India. During the period under consideration, some states were divided; we have not included the newly formed states of Chhattisgarh, Jharkhand, and Uttaranchal due to little information available for these states. Estimation of net revenue is given by

$$
\mathrm{NR}=\left\{\sum_{i=1}^{n}\left[\left(\mathrm{GV}_{i}-\mathrm{CA}_{i}\right) \times \mathrm{GA}_{i}\right]\right\} / \sum_{i=1}^{n} \mathrm{GA}_{i},
$$

where $i$ indicates a crop which takes values 1 to as much as 24 crops including five major crops (paddy, wheat, jowar, bazra, and maize) as well as nineteen minor crops (ragi, arhar, gram, groundnut, sunflower, sugarcane, cotton, onion, jute, lentil, potato, urad, sesamum, coconut, peas, soya bean, niger seed, barley, rapeseed, and mustard). $\mathrm{GV}$ is gross value per hectare of farmland for crop $i$. CA1 ${ }_{i}$ is per hectare A1 type cost which essentially covers all the explicitly purchased farm inputs for crop $i$. GA is gross cropped area for crop $i$. Notably, the above derivation of net revenue is designed for a representative state during a particular year. It may easily be replicated for the rest of the states for all individual years.

The estimation of net revenue is based on the Cost of Cultivation of Principal Crops in India published by the Directorate of Economics and Statistics, Department of Agriculture and Cooperation, Ministry of Agriculture, Government of India. This dataset by type of crops across the states covers a wide range of disaggregated information including values and costs specified in the above equation. Nominal net revenues are expressed in 1999-2000 INR (Indian Rupee, currently at US $\$ 1=60$ INR) using the agricultural GDP deflator estimated from the Reserve Bank of India database. Figure 4.3 offers the average net revenue (real) over the period across states of India.

The increasing coverage of weather stations for the specified radius may, in fact, improve upon the optimality of the regression results. Unlike the main explanatory variables, namely temperature and precipitation, the geographic and

\footnotetext{
${ }^{2}$ We have gathered consumption and price data from the Central Statistics Office and the National Sample Survey Office of India.
} 


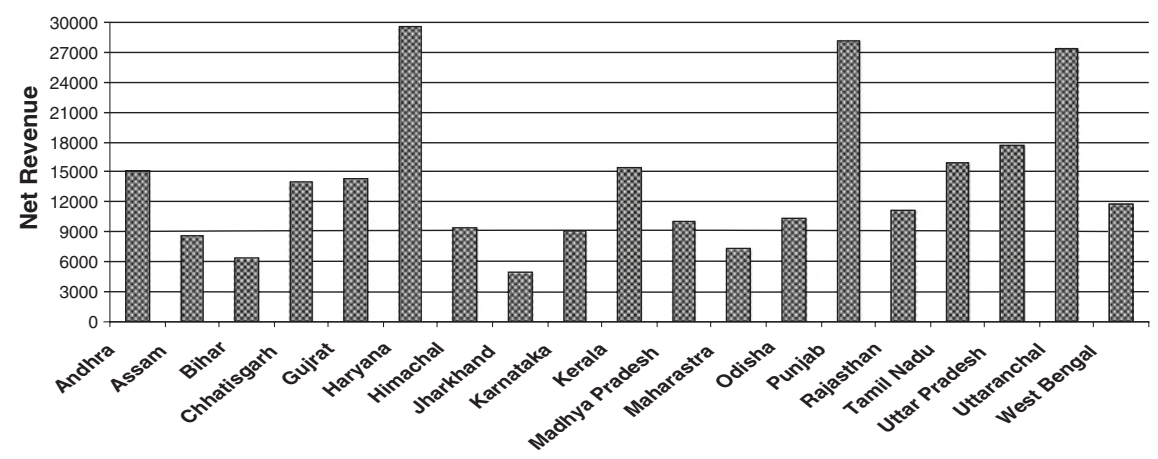

Fig. 4.3 State-level average net revenue per hectare during 1996-1997 to 2008-2009 (in INR)

socioeconomic control variables in our Ricardian model may be assessed directly from the official data sources. Before discussing the assessment of these control variables, let us explain the relevance of the model. The inputs, namely irrigation and HYV seeds, are the most important variables for modern agricultural practices following the Green Revolution in India. The irrigation intensity is measured by the share of irrigated area to cropped area. Similarly, the HYV intensity is defined as the area using HYV to the cropped area. The interaction term of HYV and irrigated areas is consequently important. Soil fertility is another crucial factor for cultivation. As per the soil map of India, ${ }^{3}$ there are six major soil types: forest and mountains, alluvial, red and yellow, black, laterite, and arid. Most of the states, however, encompass a mixture of soils with one or two predominant types. Using a soil fertility standard for mixed varieties (alluvial soil represents more fertility vis-à-vis arid soil), the soil dummies are constructed for the states. Finally, Human Development Index (HDI) and Below Poverty Line (BPL) are included (in alternate regressions) in order to estimate the adaptive capability of the farmers in response to climate changes. While the composite variable HDI controls for health, education, and financial status, the poverty level of the rural population (BPL) serves as an indicator of regional disparity.

We use a simulation technique to produce state-level annual net revenues, to be aggregated for the country in the following way:

$$
\Delta \mathrm{NR}=\sum_{\mathrm{n}=1}^{19}\left[\mathrm{NR}\left(W_{n}+\Delta W_{n}\right)-\mathrm{NR}\left(W_{n}\right)\right],
$$

where $\Delta$ represents change for a variable, say net revenue denoted by NR for any of the four representative seasonal months, $W$ is climactic variable, and $n$ stands for state. The equation, therefore, gives us the amount of net revenue change for a particular year in India.

\footnotetext{
3 The map is available online at url: www.mapsofindia.com.
} 


\subsubsection{Estimation of Climate Change Impact on Poverty}

The impact of climate change on poverty and, subsequently, the well-being of the rural population may be judged by a two-step approach: climate change-induced returns from agricultural land and then a counterfactual measure of these farmland values on consumption expenditure under alternative climate change scenarios. We start from a basic income-consumption relation for a representative rural household. Consumption expenditure at the household level mainly depends on consumption of food and non-food items, when sources of income include both farm and non-farm activities: $C=A_{L} R(W)+w L_{o}$, where consumption $(C)$ is determined by two components of income-climate $(W)$-induced farm revenue $(R)$ from the amount of farmland $\left(A_{L}\right)$ and earning from the fraction of labor $\left(L_{o}\right)$ service in the off-farm sector with wage rate $w$. Based on this model, we conduct the following regression exercise using a control variable, namely the household size (HHS):

$$
\mathrm{CEP}=\alpha+\beta_{1} \mathrm{FLR}+\beta_{2} \mathrm{OFE}+\lambda \mathrm{HHS}+u,
$$

where CEP is consumption expenditure, FLR is farmland revenue, and OFE is off-farm earning, deflated by the agricultural GDP deflator (1999-2000 base) and transformed into natural logarithm values. Household size controls for variation in the number of inhabitants.

Note that the state-level climate-induced net revenue per hectare of farmland, estimated in the previous section, needs further refinement, wherein we convert per hectare farm revenue to per month per person basis at the state level. To this end, we used gross area under cultivation and persons involved in agriculture, as (i) self-employed in agriculture, (ii) self-employed in non-agriculture, (iii) agricultural labor, (iv) non-agricultural labor, and (v) others (such as salaried). In normal circumstances, a rural household is expected to derive a larger part of its income from agriculture, supported by other sources. The non-agricultural laborers are casual off-farm wage earners, and it is easily verifiable that the wages are broadly similar as per the National Sample Survey of India (NSS) reports. Thus, the statewide average monthly income of a person from off-farm occupations is estimated from the weighted daily earnings from regular wage/salary source and casual offfarm labor's earning over a particular month. Nevertheless, owing to the unavailability of data for each year, some interpolation mechanisms have been used for normalizing the NSS dataset for each year.

\subsection{Empirical Results and Discussions}

The estimate of the impact of climate variables on agriculture using the Ricardian model is depicted in Table 4.2. This regression model is essentially a restructured functional relationship between net revenue from agriculture and climate variables across space and over time for India, while controlling for various geographic and economic variables. 
Table 4.2 Ricardian regression results for net revenue in India

\begin{tabular}{|c|c|c|c|}
\hline Variable & Coefficient & Coefficient & t-Statistic \\
\hline Constant & 198.15 & 200.03 & 18.68 \\
\hline January temperature & -172.83 & -172.84 & -3.11 \\
\hline April temperature & -360.23 & -360.23 & -5.98 \\
\hline July temperature & -205.57 & -205.57 & -4.56 \\
\hline October temperature & 157.77 & 157.77 & 16.01 \\
\hline January precipitation & 11.50 & 11.50 & 3.01 \\
\hline April precipitation & -5.67 & -5.67 & -6.53 \\
\hline July precipitation & -0.61 & -0.61 & -8.94 \\
\hline October precipitation & 8.67 & 8.67 & 6.05 \\
\hline January temperature square & -59.88 & & -17.11 \\
\hline April temperature square & 110.51 & & 3.44 \\
\hline July temperature square & -88.01 & & -2.93 \\
\hline October temperature square & -63.51 & & -8.84 \\
\hline January precipitation square & -2.32 & & -7.09 \\
\hline April precipitation square & 2.35 & & 2.71 \\
\hline July precipitation square & 0.60 & & 5.48 \\
\hline October precipitation square & 1.16 & & 2.23 \\
\hline January temperature cube & -8.75 & & -1.22 \\
\hline April temperature cube & 2.09 & & 4.14 \\
\hline July temperature cube & -7.95 & & -12.33 \\
\hline October temperature cube & -14.92 & & -2.71 \\
\hline January precipitation cube & -0.37 & & -1.17 \\
\hline April precipitation cube & 0.05 & & 1.79 \\
\hline July precipitation cube & 0.01 & & 0.52 \\
\hline October precipitation cube & 0.02 & & 3.39 \\
\hline January temperature $\times$ precipitation & -9.67 & & -5.18 \\
\hline April temperature $\times$ precipitation & 3.64 & & 2.62 \\
\hline July temperature $\times$ precipitation & -1.06 & & -1.43 \\
\hline October temperature $\times$ precipitation & -0.75 & & -0.82 \\
\hline Irrigation & 33.99 & 33.99 & 5.52 \\
\hline HYV & 28.18 & 28.18 & 11.62 \\
\hline HDI & - & 4.21 & 3.21 \\
\hline BPL & -1.47 & & -3.11 \\
\hline Soil dummy 1 & 7.04 & 7.04 & 8.18 \\
\hline Soil dummy 2 & 8.13 & 8.13 & 6.47 \\
\hline Soil dummy 3 & 3.56 & 3.56 & 2.57 \\
\hline Soil dummy 4 & 1.17 & & 1.01 \\
\hline Soil dummy 5 & 6.59 & & 5.76 \\
\hline Soil dummy 6 & -3.65 & & -2.33 \\
\hline Soil dummy 7 & -6.07 & & -0.63 \\
\hline
\end{tabular}


Table 4.2 (continued)

\begin{tabular}{l|l|c|c}
\hline Variable & Coefficient & Coefficient & t-Statistic \\
\hline Year dummy 1997 & 76.58 & & 3.05 \\
\hline Year dummy 1998 & 37.15 & & 2.12 \\
\hline Year dummy 1999 & -73.24 & -73.24 & -0.95 \\
\hline Year dummy 2000 & -30.53 & -30.53 & -1.09 \\
\hline Year dummy 2001 & -26.75 & -26.75 & -9.09 \\
\hline Year dummy 2002 & 34.13 & 34.13 & 7.40 \\
\hline Year dummy 2003 & 57.44 & 57.44 & 7.05 \\
\hline Year dummy 2004 & -45.61 & -45.61 & -0.66 \\
\hline Year dummy 2005 & 29.38 & & -0.53 \\
\hline Year dummy 2006 & 4.88 & & 0.07 \\
\hline Year dummy 2007 & 52.11 & & 2.33 \\
\hline Year dummy 2008 & 70.01 & & 0.79 \\
\hline Constant & 33.99 & & 5.52 \\
\hline R-squared & 0.87 & 0.76 & \\
\hline Sample period & $1997: 2008$ & & \\
\hline Total panel (unbalanced) observations & 229 & & \\
\hline Dependent variable & Net revenue & & \\
\hline
\end{tabular}

Not unexpectedly, the control variables offer appropriate directions. The net revenue is responsive to different types of soil as per their fertility levels. The dummy variables for all the years are significantly positive. The time dummies suggest fluctuations in annual values because of unweighted climate and economic effects. This might even suggest 'no trend' in the coefficients of year dummies.

The irrigation intensity has a positive impact on net revenue since more irrigation facilities are indeed associated with enhanced productivity and, therefore, revenue. The coefficient for HYV areas is positive, reflecting the desirable positive effect of net revenues in the course of higher productivity that followed the Green Revolution in India. Likewise, the coefficient of the composite index of human development is positive in the second regression, while the BPL effect is negative. That more poor regions will generate less net revenues in agriculture is straightforward, and the impact of climatic variations on consumption would, therefore, also be highly sensitive to that.

The regression results clearly indicate that most of the climatic factors are statistically significant. This embodies a discerning impact of the climate variables on net revenue. In addition, the importance of quadratic and interaction terms of climate reveals underlying nonlinear effects. Looking at the marginal climate effects by seasons, January, April, and July temperatures have negative influence, while the October temperature effect is positive. According to the Indian crop calendar, the summer crops for the Kharif season are usually sown in April, grown in July, and harvested in October. Likewise, October is the sowing month, January is growing, and April is harvesting for the winter crops (Rabi). The positive effect 
appearing for October alone implies that a rising temperature during the harvesting period of summer crops could possibly be favorable for the ripening process. On the other hand, rising temperature in other seasons might lead to heat stress on crop cultivation systems. For instance, incremental warmth for harvesting Rabi crops in April could cause strain on ripening of heat-sensitive winter crops like wheat. Furthermore, the October precipitation (harvesting period for summer crops) turns out to be of strictly positive influence. However, an additional bit of precipitation in pre-monsoon and monsoon seasons adversely affects crop production. But the comparative detrimental effect of supplementary monsoon rainfall is especially marginal as it usually harmonizes with the monsoon. Note that the adverse effect of higher rainfall for Kharif crops (during April) may, however, cause harm to the growth of seeds in the sowing season.

\subsubsection{Effect of Climate Change on Agriculture}

For the sensitivity analysis, we now turn to the simulation of climate change impact on net revenue for the $2{ }^{\circ} \mathrm{C}$ increase in mean temperature and $7 \%$ rise in mean rainfall. The resulting impacts by seasons are depicted in Table 4.3. As seen from the regression results, there is a considerable variation for both temperature and rainfall effects on the net revenue change. A $2{ }^{\circ} \mathrm{C}$ increase in temperature for any seasonal month when nothing else changes shows that the net revenue would decline by INR1594 (USD $\$ 1=$ INR 45 , the average exchange rate during this period) for January, INR566 for April, and INR204 for July, respectively. Conversely, these undergo increases in the month of October by approximately INR728.

In conformity with our regression results, a $7 \%$ rise in the precipitation is good for the growing period of Rabi crops and harvesting period of Kharif crops. These are associated with respective increases in the revenue by INR106 for January and INR90 for October. However, simulation of monsoon precipitation in July has almost no effect on the farm revenue. A moderately adverse effect on the revenue by approximately INR95 is observed for rising precipitation in April (during pre-monsoon season associated with the Kharif crops). Note that these simulation results for India are obtained from the average value over 13 years by aggregating statewide values. For regional patterns of agricultural response to climate change across major agricultural producing states, see Fig. 4.4 for January temperature simulation. Notably, it is just a representative of the seasonal months; the same simulating figure can be done for other seasonal months too.

Table 4.3 Simulation of temperature and precipitation effects on net revenue (in INR)

\begin{tabular}{l|r|r|r|r}
\hline & \multicolumn{1}{|l|}{ Winter } & \multicolumn{1}{c|}{ Summer } & \multicolumn{1}{c|}{ Monsoon } & \multicolumn{1}{c}{ October } \\
\hline Temperature effects $\left(+2{ }^{\circ} \mathrm{C}\right.$ increase $)$ & $-1,594.17$ & -565.64 & -204.37 & +728.09 \\
\hline Precipitation effects $(+7 \%$ increase $)$ & +105.67 & -95.37 & -8.55 & +90.34 \\
\hline
\end{tabular}

Average net revenue (per hectare in real terms) is INR 12,263.56 


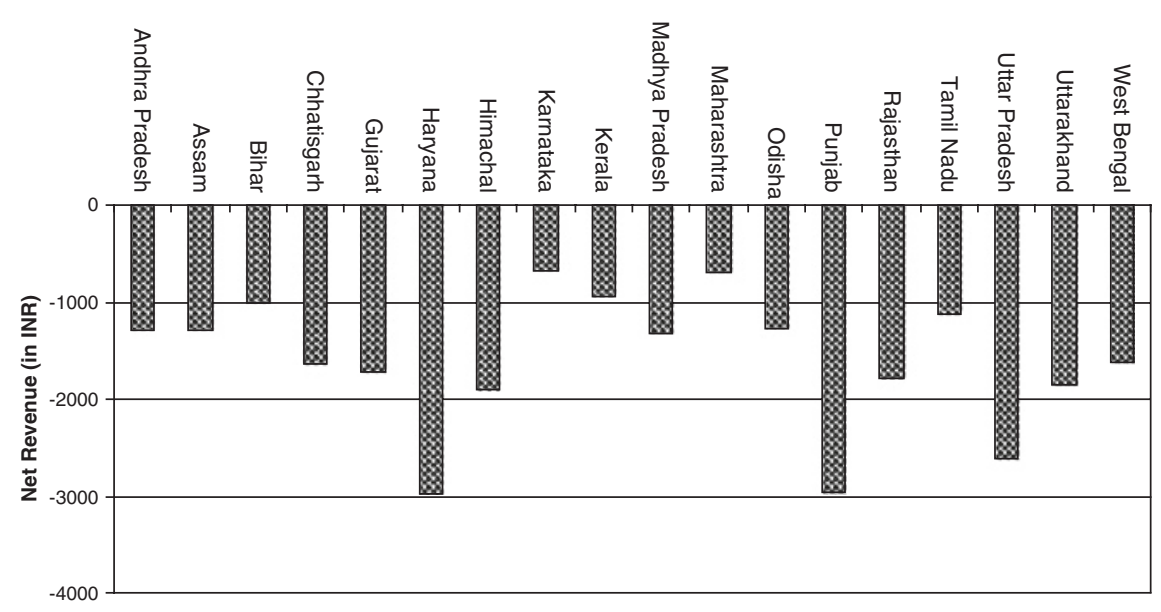

Fig. 4.4 Statewide January temperature effects (change in net revenue for $+2{ }^{\circ} \mathrm{C}$ ) in India

\subsubsection{Effect of Climate Change on Poverty and Well-Being}

The climate-induced welfare effects on the rural people who, by and large, rely on agriculture are measured by the estimated income-consumption relation depicted in Table 4.4. It is well known that the regression results are expected to show a positive and significant association between both farm and off-farm incomes and the consumption expenditures. It is also clear from the table that the comparative effect of farm earning is more than the off-farm earning as determinants of the consumption of rural agro-based commodities. Hence, poverty analysis based on climate sensitiveness in rural India may be derived from the changes in consumption level subject to climatic variations in net revenue from agriculture.

Table 4.4 Regression results for income consumption relationship in rural India

\begin{tabular}{l|l|l}
\hline Variable & Coefficient & $\mathrm{t}$-Statistic \\
\hline Net revenue & 12.02 & 6.35 \\
\hline Off-farm earning & 3.86 & 4.09 \\
\hline Household size & 0.57 & 3.91 \\
\hline Constant & 63.41 & 8.94 \\
\hline R-squared & 0.614 & \\
\hline Cross-sections used & 19 \\
\hline Sample period & $1996: 2008$ \\
\hline Total panel (unbalanced) observations & 229 \\
\hline Dependent variable & $\begin{array}{l}\text { Consumption } \\
\text { expenditure }\end{array}$ \\
\hline Method & $\begin{array}{l}\text { Pooled least squares } \\
\text { (weighted) }\end{array}$ \\
\hline
\end{tabular}


Table 4.5 Simulation of climate change effects on consumption (INR)

\begin{tabular}{l|l|l|l|l}
\hline & January & April & July & October \\
\hline Temperature effects $\left(+2{ }^{\circ} \mathrm{C}\right.$ increase $)$ & -29.35 & -15.83 & -11.20 & +17.12 \\
\hline Precipitation effects $(+7 \%$ increase $)$ & +5.76 & -8.96 & -0.16 & +4.03
\end{tabular}

Estimated average consumption (monthly per person in real terms) is INR 347.82

The sensitivity analysis shows that a simulation of climate change for $2{ }^{\circ} \mathrm{C}$ increase in temperature and $7 \%$ rise in rainfall is quite significant (Table 4.5). There is considerable variation in consumption for climate-induced changes in net revenue. The $2{ }^{\circ} \mathrm{C}$ increase in temperature, ceteris paribus, during a particular season leads to a decline in per capita monthly consumption expenditure by INR29 for January, INR16 for April, and INR11 for July, respectively, and subsequently for other months. For example, a moderately adverse effect on the consumption by approximately INR4 is observed for higher precipitation in April. Clearly, these simulations are amenable to changes in both directions, and we develop a theoretical model under the assumption that rise in temperature and decline in precipitation are the main outcomes of climate change. The reduction in consumption is still a predominant outcome of such changes, which in view of the empirical and simulation results would make a case for those monthwise specifications when lower precipitation lowers crop production.

\subsection{A Model}

The empirical results delineate that a climate shock leads to decrease in agricultural production, mainly depending on the sensitivity of the sector on climatic factors, such as temperature and rainfall. Compared to a steady-state equilibrium, it is expected that if the environmental shock leads to a rising temperature and lowers supply, the price must rise at a given level of demand. If the wages and other factor prices do not change, this should, consequently, lower real income of all factors of production. Individuals who are already vulnerable are likely to suffer owing to this change. The above reactions to climate change lead to the welfare implication we wish to derive in this model. The model actually goes beyond the typical rural economy and involves a larger canvas, wherein the urban counterparts of the rural marginal workers feature in the welfare calculations. Using a standard general equilibrium model, we exemplify that the overall welfare implications are, however, conditional on a set of critical factors that include the magnitude of climatic changes and the sensitivity of prices to such changes. To start with, consider four sectors describing the model economy. Commodity $X$ is defined as an industrial good using labor $(L)$ and capital $(K)$. There are two agricultural products, the food grains $(A)$ and the cash crops $(C)$, both of which use labor, land, and climatic factors, such as rainfall $(R)$ as inputs. There is a fourth sector, called the urban informal sector $(I)$, which uses labor and capital like the industrial units. However, 
the unorganized nature of $I$ leads to market-determined wage for the labor force. The unskilled workers in sector $I$ move between agriculture and the urban informal sector. The urban informal sector is an offshoot of jobs being rationed in the formal industrial units due to wages $(\bar{w})$ higher than the market clearing level as negotiated by the labor unions in a typical organized sector. The free mobility of labor between the other three sectors equalizes nominal wage $(w)$. We have argued at length (see Marjit and Kar 2011) that the workers moving in from the rural sector in search of urban jobs cannot wait indefinitely for a formal manufacturing job to open up. The urban informal sector helps to clear the labor market, unlike in the typical Harris-Todaro (1970)-type structures where the job acquisition rate in such industries comes with a probability based on the prevailing unemployment rate. The real wage earned by workers in the urban informal sector shall be used as a measure of well-being among the poor. The price of the informal commodity or service is held as the numeraire, $P_{I} \equiv 1$. All other prices $P_{i}, i=X, A, C$ are expressed in terms of the numeraire.

The return to capital is also determined by its mobility between the formal and informal units. We further argue that the climatic factor input, namely rainfall, cannot be directly priced. Instead, per unit value of water resources is based on a shadow price of, say, the price of groundwater or of the irrigation facility provided by the state and given by $\rho$. We use the water resources as an outcome of climate shocks (related literature suggests that global warming is largely responsible for changes in the level of water resources available to farmers). On the other hand, rent on land $(\tau)$ is determined from Eqs. (4.6) and (4.7) along with full employment conditions given by (4.9)-(4.12). Technology is neoclassical with diminishing marginal productivity and CRS, markets are competitive, and resources are fully employed. The following equations describe the model and use conventional symbols, such as $a_{i j}$ representing input-output coefficients.

$$
\begin{gathered}
\bar{w} a_{L X}+r a_{K X}=P_{X}^{*} \\
w a_{L A}+\tau a_{T A}+\rho a_{R A}=P_{A} \\
w a_{L C}+\tau a_{T C}+\rho a_{R C}=P_{C}^{*} \\
w a_{L I}+r a_{K I}=P_{I} \equiv 1 \\
a_{L X} X+a_{L A} A+a_{L C} C+a_{L I} I=L \\
a_{K X} X+a_{K I} I=K \\
a_{T A} A+a_{T C} C=T \\
a_{R A} A+a_{R C} C=R \\
D_{A}\left(P_{A}\right)=S_{A}\left(P_{A}\right)
\end{gathered}
$$


Equations (4.5)-(4.13) determine nine unknown variables $w, r, \tau, \rho, X, A, C$, and $I$ as in standard-specific factor models, where input-output coefficients are given by $a_{i j}=a_{i j}\left(w_{i} / w_{n}\right)_{j} ; i, n=L, K, T, R$ and $j=X, A, C, I ; i \neq n$ and factor endowments are $L, K, T$, and $R$. For example, given the internationally traded price of $X$ and the negotiated wage, we can determine $r$, the return to per unit capital. Given the return to capital and the unit price of the informal good, it is easy to determine the informal wage, $w$. Free mobility of labor settles wage at $w$ in all the sectors. Equation (4.9) offers the equality between demand and supply of agricultural commodities in the home country, determining the price of this non-traded good in the process. It can also be assumed that the agricultural food grains are traded along with the cash crops, denoted by $C$. In that case, the international price of $A$ is given for a small open economy, Eq. (4.9) is superfluous, and all the factor prices are determined from a system of eight equations and eight unknown variables.

Let us consider an environmental shock to this economy, as many in the developing world are facing in reality. If it is a pure rise in temperature due to emission of green house gases (GHG), think of $R$ as a temperature parameter, any rise in which lowers output. Technically speaking, this is the Rybczynski effect of an endowment shock working in the opposite direction. Alternatively, if $R$ is treated as rainfall, excessive rainfall causes similar damage to agricultural crops via flooding. So, let us assume that $R$ is rainfall, which becomes scarce owing to higher average annual temperatures - a globally accepted hypothesis of the effect of global warming. This is naturally in agreement with some of the empirical observations discussed earlier. In effect, $R$ falls and we shall now calculate the effects on various agricultural products, industrial products, factor prices, and the changes in aggregate income.

Using (4.8), and taking percentage changes, such that, $\hat{A}=\frac{\mathrm{d} A}{A}$, we get

$$
\lambda_{R A}\left[\hat{a}_{R A}+\hat{A}\right]+\lambda_{R C}\left[\hat{a}_{R C}+\hat{C}\right]=\hat{R} .
$$

In Eq. (4.10), $\hat{R}<0$, and since the endowment effect is primary (which will change prices as a secondary effect), it is likely to affect production of $A$ and $C$ directly, other things remaining constant. Using (4.7) and (4.10) at unchanged prices

$$
\begin{aligned}
& \lambda_{R A} \hat{A}+\lambda_{R C} \hat{C}=\hat{R} \\
& \lambda_{T A} \hat{A}+\lambda_{T C} \hat{C}=\hat{T} .
\end{aligned}
$$

Solving for $(\hat{A}, \hat{C})$ combination from (4.11) and (4.12) yields

$$
\hat{A}=\frac{\lambda_{T C} \hat{R}}{\left[\lambda_{R A} \lambda_{T C}-\lambda_{T A} \lambda_{R C}\right]}<0, \quad \text { if } f, \frac{\lambda_{R A}}{\lambda_{T A}}>\frac{\lambda_{R C}}{\lambda_{T C}} \Rightarrow \Delta=\left[\lambda_{R A} \lambda_{T C}-\lambda_{T A} \lambda_{R C}\right]>0 .
$$

Condition (4.13) states that the agricultural product $A$ is more rain dependent than $C$. It follows that $\hat{C}=\frac{-\lambda_{T A} \hat{R}}{\left[\lambda_{R A} \lambda_{T C}-\lambda_{T A} \lambda_{R C}\right]}>0$. The decline in water resources, thus, implies that the agricultural product which is heavily dependent on water will face 
lower output in the next period, whereas the other product which uses land resources more extensively shall benefit. The intuition is straightforward. If lack of water hinders production in $A$, then some of the land area under cultivation of $A$-type crop will be released and taken up by $C$-type agricultural product. Therefore, output of $C$ must rise in the following period. Note that this does not have to be a comparison of food grains and cash crops; it can also represent the observed transition from Kharif to Rabi crops in the case of India. The latter is much less dependent on rainwater, essentially because it is cultivated in the winter months.

Proposition 1 If climate shocks in the medium to long run lower production of one type of crop while expanding production of other types and if the agricultural employment falls overall, then the formal industrial sector should also be adversely affected directly through resource constraints.

Proof Intuitively, one could argue that the changes in production shall not remain confined within the boundaries of the agricultural sector only. Suppose the shift in production from $A$ to $C$ lowers employment in agriculture. Therefore, the employer of all surplus labor, the so-called informal sector, will have to readjust $w$ to accommodate more workers. This, in turn, must raise capital's return in this sector as well as the formal industrial sector. This opens up a possibility that the formal sector will have to shrink. The reverse happens if employment rises and draws labor out of the informal sector into expanding agricultural sector. This should raise the informal wage and lower the return to capital. Consequently, given intensity assumptions (suppose the formal industrial sector is more capital intensive), one sector should expand and the other shrink.

The fall in output and supply of A-type agricultural products at unchanged demand should inevitably raise the price of that commodity via Eq. (4.13). We use this price effect to calculate the changes in factor prices from Eqs. (4.5)-(4.7). Note that since $P_{X}$ does not change and $\bar{w}$ remains same, the rental rate is unaffected in (4.5). Hence, using (4.8), it is immediate that the nominal wage of workers remains unchanged as well. Therefore, the effect of a rise in $P_{A}$ restricts itself to changes in $(\rho, \tau)$ combinations from Eqs. (4.6) and (4.7). The international price of commodity $C$ is also held constant.

Once again taking percentage changes and retaining the factor intensity assumption,

$$
\hat{\tau}=\frac{-\theta_{T A} \hat{P}_{A}}{\left[\theta_{R A} \theta_{T C}-\theta_{T A} \theta_{R C}\right]}<0 \quad \text { and } \quad \hat{\rho}=\frac{\theta_{T C} \hat{P}_{A}}{\left[\theta_{R A} \theta_{T C}-\theta_{T A} \theta_{R C}\right]}>0,
$$

where $\theta=\left[\theta_{R A} \theta_{T C}-\theta_{T A} \theta_{R C}\right]>0$. The derivations in (4.14) offer the effects of a deficient rainfall on returns to factors that are quite important and unique for agricultural production. Note that what we suggest here is a long-run relationship. If shortage of rainfall leads to drought in a particular year, then the production pattern is unlikely to get affected on a more permanent basis as we contemplate would be the tendency in this case. 
Proposition 2 A decline in precipitation would unambiguously lower welfare in terms of consumption if the negative employment (and income) effect in the food grain sector is strong and outweighs that in the informal sector.

Proof We begin by calculating the welfare implications. Assume that the direct utility function for the group of identical workers in the country be $V=V\left(D_{X}, D_{A}, D_{C}, D_{I}\right)$, where the arguments are consumption of all commodities produced at home. Thus, we measure overall change in welfare by calculating change in consumption levels domestically. Note that the condition of balanced trade requires that

$$
P_{X}^{*} \mathrm{~d} D_{X}+P_{A} \mathrm{~d} D_{A}+P_{C}^{*} \mathrm{~d} D_{C}+\mathrm{d} D_{I}=P_{X}^{*} d X+P_{A} d A+P_{C}^{*} d C+d I .
$$

Rearranging, $P_{A} d D_{A}+d D_{I}=P_{X}^{*}\left(d X-d D_{X}\right)+P_{A} d A+P_{C}^{*}\left(d C-d D_{C}\right)+d I$. Define the poor man's consumption basket and related welfare by

$$
d \Omega=P_{A} d D_{A}+d D_{I}
$$

Since commodities $A$ and $I$ are non-traded, while $X$ and $C$ are traded internationally, using (4.19) and (4.20), we get

$$
d \Omega=P_{X}^{*}\left(d M_{X}\right)+P_{C}^{*}\left(d M_{C}\right)+P_{A} d A+d I,
$$

where the right-hand side of Eq. (4.21) represents total change in output, with $M_{j}$ defining net import demand for good $j$. In our case, it is safe to assume that $X$ is imported, while $C$ is exported.

$$
\text { Note that } P_{A} d A+d I=w\left(d L_{I}+d L_{A}\right)+\rho d R \text {. }
$$

However, the net import demand functions should be rewritten as

$$
\begin{gathered}
M_{j}=M_{j}\left(P_{j}^{*}, P_{k}^{*}, \Omega\right), d M_{j}=S_{j j} d P_{j}^{*}+S_{j k} d P_{k}^{*}+\mu_{j} d \Omega=\mu_{j} d \Omega \\
\quad \text { as } \quad d P_{j}^{*}=d P_{k}^{*}=0,
\end{gathered}
$$

where $S_{j j}=\frac{d M_{j}}{d P_{j}^{*}} S_{j k}=\frac{d M_{j}}{d P_{k}^{*}}$ are the own price and cross-price effect, respectively, while $\mu_{j}=\frac{\delta M_{j}^{j}}{\delta \Omega}>0$ is the income effect.

Since $\mu_{j}=\frac{m_{j}}{P_{j}^{*}}$, where $m_{j}$ represents the marginal propensity to consume import $\operatorname{good} j$, using (4.17),

$$
\begin{gathered}
d \Omega=P_{X}^{*}\left(\mu_{X} d \Omega\right)+P_{C}^{*}\left(\mu_{C} d \Omega\right)+P_{A} d A+d I \\
d \Omega\left(1-P_{X}^{*} \mu_{X}-P_{C}^{*} \mu_{C}\right)=P_{A} d D_{A}+d D_{I}
\end{gathered}
$$

or

$$
d \Omega=\frac{1}{\left(1-P_{X}^{*} \mu_{X}-P_{C}^{*} \mu_{C}\right)}\left[w\left(d L_{I}+d L_{A}\right)+\rho d R\right] .
$$

Note that $0<\left(1-P_{X}^{*} \mu_{X}-P_{C}^{*} \mu_{C}\right)<1$ as the sum of mpc in $X$ and $C$ must be $<1$.

Therefore, 


$$
\frac{d \Omega}{d R}=\frac{1}{\left(1-P_{X}^{*} \mu_{X}-P_{C}^{*} \mu_{C}\right)}\left[w\left(\frac{d L_{I}}{d R}+\frac{d L_{A}}{d R}\right)+\rho\right] .
$$

Finally,

$$
\frac{d \Omega}{d R} \frac{>}{<} 0, \text { iff, }\left[w\left(\frac{d L_{I}}{d R}+\frac{d L_{A}}{d R}\right)+\rho\right] \frac{>}{<} 0 .
$$

Rearranging,

$$
\frac{d \Omega}{d R} \frac{>}{<} 0, \quad \text { iff, } \quad\left[w \frac{d L_{I}}{d R}+\rho\right] \frac{>}{<}-\left[w \frac{d L_{A}}{d R}\right] .
$$

Here, $w \frac{d L_{I}}{d R}$ is the income gain accrued by joining the informal segment, while $w \frac{d L_{A}}{d R}$ is the income loss among agricultural workers.

\subsection{Concluding Remarks}

We found a discerning impact of the climate variables on net revenue and, hence, well-being of the rural people. Looking at the marginal climate effects by seasons, January, April, and July temperatures have a negative influence, while the October temperature effect is positive. Our results show that the rainfall coefficients move in the expected direction, though not as intensively as one expects with temperature. However, simulation of monsoon precipitation in July has almost no effect on the farm revenue. Finally, we found a moderate variation in consumption for climate-induced change in net revenue. To address the challenges on sustainable economic development and poverty, adaptation and mitigation strategies are required and may include financial incentives for improving land management, maintenance of carbon content, and efficient use of fertilizers and irrigation. These incentives will have synergies toward sustainable development and create efforts to reduce vulnerability. The generalized model also showed that the welfare implications of climate change for workers are not unambiguous. The overall welfare gain is largely negative if the income gain among the informal workers is outweighed by the loss to the agricultural workers, particularly in comparison with the initial rental value of the land resources. Future empirical evidence on the welfare implications of climate change may benefit from the construction presented in this chapter.

Acknowledgments The authors are indebted to the South Asia Network of Economic Research Institutes (SANEI) for facilitating this study through a financial grant and reviews. Comments from T.N. Srinivasan and Wahiduddin Mahmud are gratefully acknowledged. The authors thank an anonymous reviewer of this volume for suggestions with chapter guidelines. Research assistance by Shruti Chakraborty is also duly acknowledged. The usual disclaimer applies. 
Open Access This chapter is distributed under the terms of the Creative Commons Attribution Noncommercial License, which permits any noncommercial use, distribution, and reproduction in any medium, provided the original author(s) and source are credited.

\section{References*}

Brine K, Liechenko R, Kelkar U, Venema H, Aandahl G, Tompkins H (2004) Mapping vulnerability to multiple stressors: climate change and globalization in India. Glob Environ Change 14:303-313

Forsyth T (2000) Vulnerability to climate change: theoretical concerns and a case study from Thailand. In: Environment and natural resource programme. Discussion paper. Kennedy School of Government, Harvard University

Harris JR, Todaro MP (1970) Migration, unemployment and development: a two-sector analysis. Am Econ Rev 60(1):126-142

Hertel TW, Rosch SD (2010) Climate change, agriculture, and poverty. Appl Econ Perspect Policy 32(3):355-385

IPCC (2012) Managing the risks of extreme events and disasters to advance climate change adaptation. In: Field CB, Barros V, Stocker TF, Qin D, Dokken DJ, Ebi KL, Mastrandrea MD, Mach KJ, Plattner G-K, Allen SK, Tignor M, Midgley PM (eds) A special report of working groups I and II of the intergovernmental panel on climate change. Cambridge University Press, Cambridge

Jacoby H, Rabassa M, Skoufias E (2011) On the distributional implications of climate change: the case of India. Policy research working paper. World Bank, Washington

Kumar KSK, Parikh J (2001) Indian agriculture and climate sensitivity. Glob Environ Change $11: 147-154$

Kurukulasuriya P, Mendelsohn R (2008) A Ricardian analysis of the impact of climate change on African cropland. Afr J Agric Resour Econ 2(1):1-23

Lobell DB, Burke MB (2010) On the use of statistical models to predict crop yield responses to climate change. Agric For Meteorol 150(11):1443-1452

Marjit S, Kar S (2011) The outsiders: economic reform and informal labour in a developing economy. Oxford University Press, Oxford

Mendelsohn R, Nordhaus W, Shaw D (1994) The impact of global warming on agriculture: a Ricardian analysis. Am Econ Rev 84(4):753-771

Nhemachena C, Hassan R, Kurukulasuriya P (2010) Measuring the economic impact of climate change on African agricultural production systems. Clim Change Econ 1(1):33-55

Palatnik RR, Roson R (2009) Climate change assessment and agriculture in general equilibrium models: alternative modeling strategies. Working paper no. 67.09, FEEM (Fondazione Eni Enrico Mattei), Italy

Ricardo D (1817) On the principles of political economy and taxation. John Murray, London

Sanghi A, Mendelsohn R (2008) The impacts of global warming on farmers in Brazil and India. Glob Environ Change 18:655-665

Schlenker W, Roberts MJ (2009) Nonlinear temperature effects indicate severe damages to U.S. crop yields under climate change. Proc Nat Acad Sci USA (PNAS) 106(37): 15594-15598. URL http://www.pnas.org/content/106/37/15594

Schmidhuber J, Tubiello FN (2007) Global food security under climate change. Proc Nat Acad Sci USA (PNAS) 104(50): 19703-19708. URL http://www.pnas.org/content/104/50/19703

Seo N, Mendelsohn R (2007) A Ricardian analysis of the impact of climate change on Latin American farms. Policy research working paper 4163. The World Bank, Washington

\footnotetext{
* ADB recognizes "China" as the People's Republic of China.
} 
Tirado MC, Cohen MJ, Aberman N, Meerman J, Thompson B (2010) Addressing the challenges of climate change and bio-fuel production for food and nutrition security. Food Res Int 43:1729-1744

Narain S, Ghosh P, Saxena NC, Parikh J, Soni P (2009) Climate change: perspectives from India. United Nations Development Programme, India

Zhai F, Lin T, Byambadorj E (2009) A general equilibrium analysis of the impact of climate change on agriculture in the People's Republic of China. Asian Development Rev 26(1):206-225 